\title{
Reply to the Discussion by Chen on "Traffic-induced vibrations of frame structures"1
}

\author{
Marija Nefovska-Danilovic and Mira Petronijevic
}

The authors appreciate the discusser's interest in their paper. The responses to the discusser's questions are given as follows:

\section{Numerical study}

We agree with the discusser's observation that the largest displacement of a twelve-storey frame occurs at the fourth storey under the tram traffic. However, the largest horizontal displacements of a six-storey frame occur at the top floor under both tram and truck traffic (Fig. 14 in the paper). In addition, the largest horizontal displacement of a twelve-storey frame under the truck traffic also occurs at the top floor. Horizontal displacement spectra of six and twelve storey frames are given in Figs. 1-4. Obviously, the largest displacement amplitudes occur at the lower horizontal vibration modes for both six and twelve storey frames (Table 1).

\section{Validation of the numerical model}

The numerical model presented in the paper has been validated using the results of vibration measurements performed on the two, six, and twelve storey buildings. The geometry and material properties of the buildings were proximate to the idealized frames used in the numerical prediction. Tuning of the input geometric and material properties of the frames has not been carried out in the paper. Therefore, the validation showed the discrepancies between the measured and predicted vibrations. In addition, strong wind during the vibration measurements of the twelve storey frame was one of reason for the discrepancies between the predicted and measured vibrations. In general, the accurate prediction of traffic-induced vibration is virtually impossible, due to many uncertainties related to an existing building (Ungar 2010). Therefore, any analytical or numerical model needs to be calibrated. Having all that in mind, the obtained results can be accepted as reliable. Consequently, the conclusion is that the spectral element method (SEM) is applicable for the prediction of building vibration, but the applied model needs improvements to provide greater reliability of the predicted vibration levels.

\section{SEM discussion}

The SEM is based on the spectral representation of the displacement field and on the exact solution of the governing differential equations of motion defined in the frequency domain. For onedimensional elements like beams and bars the displacement field of the spectral element represents the exact solution of the partial differential equation of motion. Therefore, only one element can exactly represent the dynamic behavior of a structural member at any frequency.
Fig. 1. Horizontal displacement spectra for six-storey frame, tram traffic.

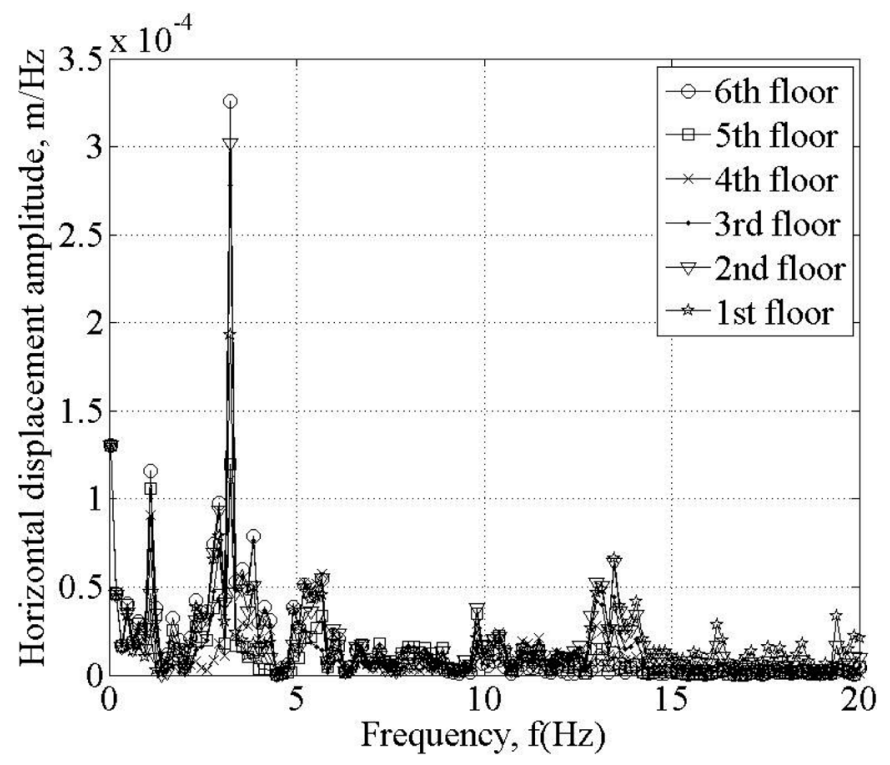

For two-dimensional elements like plates it is not possible to obtain the exact solutions of the governing equations of motion that satisfy all boundary conditions. In addition, the boundary conditions are continuous functions of spatial variables. To find a solution of a problem, plate displacements are presented as infinite Fourier type series (Kulla 1997). For practical purposes, the series have to be truncated, which introduces an error. Consequently, the solutions are approximate and satisfy the prescribed degree of accuracy. Nevertheless, this is not a serious drawback, since the truncation point can be easily controlled by the user without re-meshing of the structure. Kulla was the first who developed high precision continuous element for transverse vibration analysis of plates with arbitrary boundary conditions and applied it to dynamic response analysis of plate assemblies subjected to harmonic line load. Casimir et al. (2005) built the dynamic stiffness matrix of two-dimensional Kirchoff's plate element with free edges using Gorman's superposition method (Gorman 1978). Coupling of one-dimensional and two-dimensional spectral elements has been efficiently applied in the dynamic response analysis of frame structures subjected to traffic-induced vibrations by Nefovska-Danilovic (2012).

Received 12 June 2013. Accepted 30 June 2013.

M. Nefovska-Danilovic and M. Petronijevic. Faculty of Civil Engineering, University of Belgrade, Bulevar kralja Aleksandra 73, 11000 Belgrade, Serbia.

Corresponding author: Marija Nefovska-Danilovic (e-mail: marija@grf.bg.ac.rs).

${ }^{1}$ Appears in the Canadian Journal of Civil Engineering, 2013, 40: doi:10.1139/cjce-2013-0203. 
Fig. 2. Horizontal displacement spectra for six-storey frame, truck traffic.

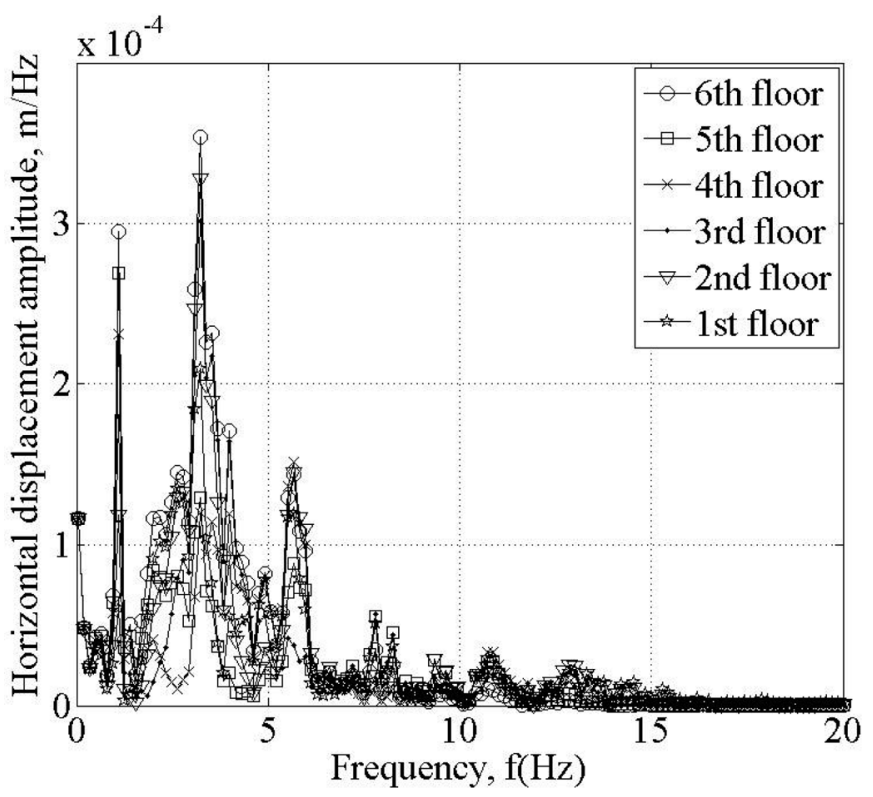

Fig. 3. Horizontal displacement spectra for twelve-storey frame, tram traffic.
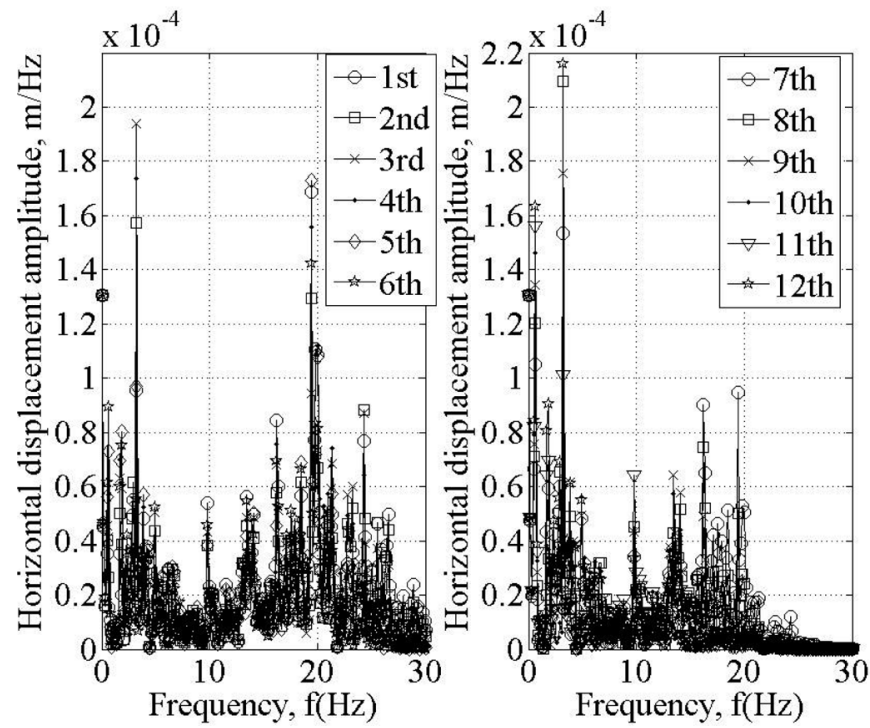

The application of spectral elements significantly reduced the number of the unknowns, increased the accuracy of the numerical results, and decreased the computational time in comparison with the conventional finite element method (FEM). High preci-
Fig. 4. Horizontal displacement spectra for twelve-storey frame, truck traffic.
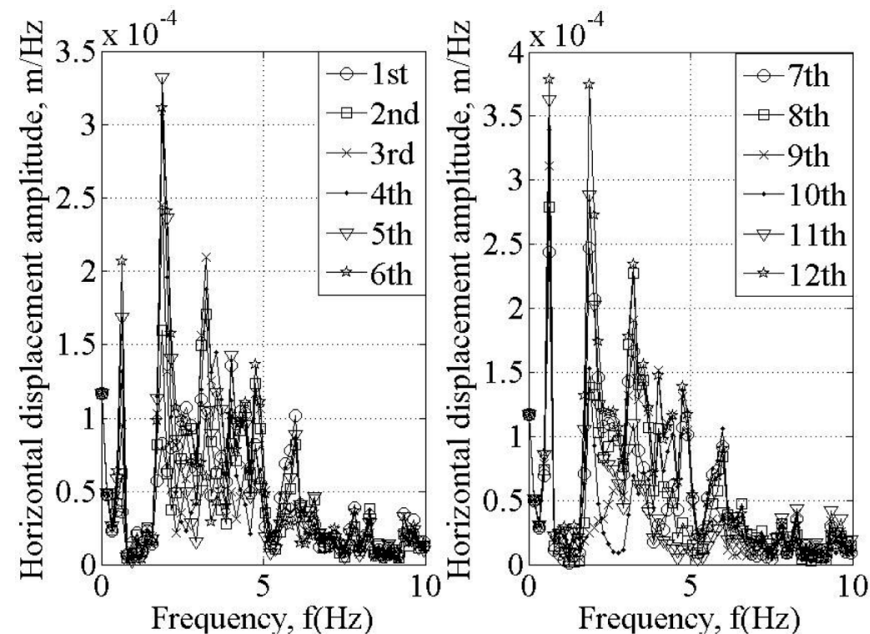

Table 1. Maximum horizontal displacements and corresponding frequencies.

\begin{tabular}{llllll}
\hline & Tram & & & Truck \\
\cline { 2 - 3 } \cline { 5 - 6 } Frame & $\begin{array}{l}\text { Max. displacement } \\
\left(\times 10^{-6} \mathrm{~m}\right)\end{array}$ & $f(\mathrm{~Hz})$ & & $\begin{array}{l}\text { Max. displacement } \\
\left(\times 10^{-6} \mathrm{~m}\right)\end{array}$ & $f(\mathrm{~Hz})$ \\
\hline 2 & 1.42 & 2.3 & & 5.25 & 2.3 \\
6 & 1.08 & 3.2 & & 3.0 & 3.2 \\
12 & 1.75 & 3.2 & 2.83 & 0.64 \\
\hline
\end{tabular}

sion and run time are the strongest points of the SEM (Kulla 1997). The application of the SEM is especially suitable in the preliminary design phase.

\section{Conclusions}

The frequency range for truck traffic from 3 to $6 \mathrm{~Hz}$ corresponds to the predominant frequency range for ground displacements, whereas the frequency range between 3 and $27 \mathrm{~Hz}$ corresponds to the predominant frequency range for ground velocities.

\section{References}

Casimir, J.B., Kevorkian, S., and Vinh, T. 2005. The dynamic stiffness matrix of two-dimensional elements: Application to Kirchhoff's plate continuous elements. Journal of Sound and Vibration, 287: 571-589. doi:10.1016/j.jsv.2004. 11.013.

Gorman, D.J. 1978. Free vibration analysis of the completely free rectangular plate by the method of superposition. Journal of Sound and Vibration, 57: 437-447. doi:10.1016/0022-460X(78)90322-X.

Kulla, P.H. 1997. High precision finite elements. Finite Elements in Analysis and Design, 26: 97-114. doi:10.1016/S0168-874X(96)00073-X.

Nefovska-Danilovic, M. 2012. Dynamic analysis of soil-structure system using spectral element method. Doctoral dissertation, University of Belgrade, Faculty of Civil Engineering, Belgrade.

Ungar, E.E. 2010. Questions regarding the prediction of building vibrations. Sound and Vibration, 44(6): 12-15 